\title{
A study on the relationship of college students' personal projects to subjective well-being
}

Wang, Hong $\bowtie$

Faculty of Education, Southwest University, China (57179149@qq.com)

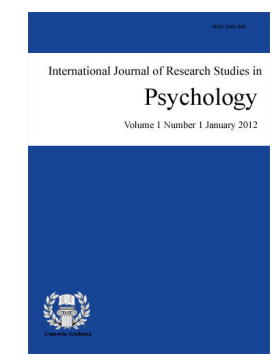

Accepted: 27 October 2015 Online ISSN: 2243-769X

OPEN ACCESS

\section{Abstract}

This study aimed at exploring the relationship between goal-directed activities and subjective well-being through Personal Projects Analysis (PPA). 316 college students completed the Personal Projects Analysis (PPA), Satisfaction with Life Scale (SWLS) and Scales of Pleasant and Unpleasant Affect. The results showed that participants who reported higher levels of SWLS and pleasant affect rated their personal projects significantly higher on PPA factors reflecting Project Meaning, Project Control and Project Interpersonal Relationship than did participants who reported lower levels of subjective well-being. While PPA factor Project Control emerged as a reliable predictor of SWLS, factor Project Meaning did as a reliable predictor of positive affect. Project Strain appeared to have no significant effects on subjective well-being. The results suggested that subjective well-being is associated with pursuing personal projects that are meaningful, better controlled, and supported by others.

Keywords: goal-directed activates; Personal Projects Analysis (PPA); Satisfaction with Life Scale; affect; subjective well-being 


\section{A study on the relationship of college students' personal projects to subjective well-being}

\section{Introduction}

Subjective well-being or happiness is the central objective of positive psychology (Seligman, 2002). It refers to both positive feelings and to positive states (Carr, 2004), or to people's overall evaluations of life such as evaluations of life satisfaction and evaluations of marriage, etc. (De Neve, 1999). A commonly accepted theory is that subjective well-being can be identified as an affective component, which is usually further divided into pleasant affect and unpleasant affect (Diener \& Emmons, 1984), and a cognitive component, which is referred to as life satisfaction (Andrews \& Withey, 1976). Affect and life satisfaction appear to be equal important to research on subjective well-being. Although satisfaction and affect components can be separated (Andrews \& Withey, 1976; Stock, Okun, \& Benin, 1986), they are at least moderately correlated, and a number of measures of subject well-being include both components (Chamberlain, 1988).

Subjective well-being is associated with goal-related activities or personal goals. Diener (1984) found that individual's behaviors can be best understood by examining goals. Jennings and Dietz (2003) argued that well-being could be understood as a positive reward by controlling the environment which was closely associated with active and positive goal activities. In addition, the types and the structure of one's goals and the rate of progress toward one's goals can all potentially affect one's emotions and life satisfaction (Austin \& Vancouver, 1996). There are also other researches on the relationships between personal goals and well-being in terms of goal appraisals (Brunstein, 1993; Emmons, 1991; Heckhausen, 1999; Karoly \& Anderson, 2000; Little, 1989; Salmela-Aro \& Nurmi.1997).

Personal goals has been conceptualized in terms of different aspects such as personal strivings (Emmons, 1986), life tasks (Cantor et al., 1987) and personal projects (Little, 1983). Among these goal-directed units, personal projects is unique and representative as little (1983) developed a methodology for analyzing personal projects called personal projects analysis (PPA). An advantage of personal projects as units of analysis is that they are simultaneously personally meaningful and ecologically sensitive to the shifting context of daily life (Little, 1987, 1993). Personal Projects Analysis also provides a flexible methodological foundation by using an integrative unit of analysis and taking into consideration the pursuit of multiple goals (Presseau et al., 2008).

There are studies on the relationships between personal projects and well-being. Little (1983) found that well-being was related to features of actions intended to achieve personal projects. Other studies showed that there was a significant difference between participants who scored higher on life satisfaction and those who scored lower in terms of viewing their idiosyncratic personal projects (Palys \& Little, 1983). Generally, studies on relationships of personal projects to well-being indicated that project factors such as control and stress significantly affect well-being. For example, personal project stress is associated with project difficulty, low progress and accomplishment, time pressure and anxiety (Little, 1989; Pychyl \& Little, 1998; Wallenius, 1999); Perceived Strain, Mastery-Control and Self-Involvement were reliable predicators of psychological distress and psychological well-being (Ruehlman \& Wolchik, 1988). Other studies have shown that goal efficacy in personal projects is related to happiness (McGregor \& Little, 1998) and depressed and nondepressed participants perceived their personal projects significantly differently (Lecci, Karoly, Briggs, \& Kuhn, 1994).

Although a number of studies indicate that perceptions of personal projects have been linked to well-being, researchers disagreed about which is the most significant factor that causes well-being. Some emphasize projects meaning or controlling, other focus on emotions. Samples of particular groups of people whose lives are typical are seldom taken into consideration in terms of exploring the meaningful relationships between personal projects and well-being. For example, college students are very special group with respect to personal projects though a sample of them as participants of a psychological study is, in most cases, considered limited. The reason that 
college student participants are important in this study is not because they are easily asked as participants but because their lives are relatively simple and mostly center on learning. That is, types of students' personal projects may be more focused than those of other groups of people. Furthermore, college students' attitudes towards learning may be different from those of other people as well. For example, some other people may feel very stressful when dealing with reading and studying whereas college students may feel less stressful under similar circumstances. In other words, what can make college students feel stressful may not be their perceptions of or carrying out those goal-related activities but something else, thus making their personal projects unique and worth studying.

This study was based on Little's (1983, 1998) Personal Projects Analysis. We expected that college students' life satisfaction and affect would be associated with features of their idiosyncratic, goal-oriented pursuits. We hypothesized that college students who score higher on life satisfaction and positive affect would report higher scores on all dimensions of personal projects except for dimension of project difficulty, challenge and stress. We also hypothesized that project meaning and project control, rather than project stress would be reliable predicators of subjective well-being.

\section{Method}

\subsection{Participants}

The sample of the study comprised of 316 college students recruited from three western universities in China (Southwest University, Sichuan University, and Chongqing Technology and Business University) between 17 and 26 years of age, which included 133 male students, 179 female students and 4 not specified. Among them, there were 46 freshmen, 105 sophomores, 136 juniors and 29 seniors.

\subsection{Measures}

The Satisfaction with Life Scale (SWLS; Pavot \& Diener, 1993) is a 5-item scale of assessing satisfaction with the respondent's life as a whole. The scale does not assess satisfaction with life domains such as health or finances but allows subjects to integrate and weight these domains in whatever way they choose. Participates rated the extent to which they agreed with each item on a 1-7 scale ranging from strongly disagree to strongly agree. The SWLS has been examined for both reliability and sensitivity, which shows strong internal reliability and moderate temporal stability. Diener et al. (1985) reported a coefficient alpha of 0.87 for the scale and a 2-month test-retest stability coefficient of 0.82 .

Emotional experience was measured by asking college students how much of the time during the past month they felt four pleasant (joy, affection, pride, and contentment) and four unpleasant (fear, anger, guilt, and sadness) emotions (Suh, Diener, Oishi, et al., 1998). Participants used a 7-point scale that ranged from 1 (never) to 7 (always) to indicate how frequently they felt each emotion. The PA (Positive Affect) score was obtained by summing the scores of the four pleasant emotion items, and the NA (Negative Affect) by summing the scores of the four unpleasant emotion items similarly. The median alpha coefficients for PA and NA were 0.67 and 0.65 , respectively, across the 40 nations.

We used a revised version of Little and Gee (2007) Personal Project Analysis (PPA) to encourage college students to describe their current personal projects in response to an instruction followed by five examples such as " try to pass the English exam", "organize a meeting" and "find a girlfriend/boyfriend". Students were asked to write down the ten most salient projects and rated each of them on 15 dimensions included in Little's scheme. These dimensions include importance, visibility of project to others, value congruency, self-identity, control, expected positive outcome, progress, absorption, responsibility, other's view of importance of project, support, difficulty, challenge, time adequacy, and stress. We also provided definitions of each dimension along with the instrument. Using any number between 0 to 10, students rated all eight projects in terms of 15 dimensions. For 
Wang, H.

example, to assess the importance dimension, students would rate how important it was to carry out or think about each project $(10=$ very important, $0=$ not important at all).

\section{Results}

We performed a principal components factor analysis on the mean scores of the 15 Personal Project dimensions followed by a varimax rotation. Four factors with eigenvalues over 1.00 emerged from the solution, which combined to account for $70.30 \%$ of the variance in the PPA dimensions. Dimensions loading on Factor 1 (importance, responsibility, value congruency, and Self-identity ) reflected Project Meaning. Dimensions loading on Factor 2 (control, expected outcome, progress, absorption, and Time adequacy) reflected Project Control. Factor 3 was labeled Project Interpersonal Relationship, reflected by visibility of project to others, other's view of importance of project and support. Finally, dimensions loading on Factor 4 (difficulty, challenge, and stress) reflected Project Strain. Internal consistencies were 0.873 for Project Meaning, 0.885 for Project Control, 0.719 for Project Interpersonal Relationship and 0.664 for Project Strain. Table 1 provides the factor loadings for each dimension.

Table 1

Factor loading for Personal Projects Dimensions $(N=316)$

\begin{tabular}{|c|c|c|c|c|}
\hline \multirow[b]{2}{*}{ Dimension } & \multicolumn{4}{|c|}{ Factor } \\
\hline & 1 & 2 & 3 & 4 \\
\hline Importance & 0.742 & & & \\
\hline Responsibility & 0.725 & & & \\
\hline Value congruency & 0.799 & & & \\
\hline Self-identity & 0.849 & & & \\
\hline Control & & 0.592 & & \\
\hline Expected outcome & & 0.669 & & \\
\hline Progress & & 0.810 & & \\
\hline Absorption & & 0.666 & & \\
\hline Time adequacy & & 0.782 & & \\
\hline Visibility of project to others & & & 0.821 & \\
\hline Other's view of importance of project & & & 0.653 & \\
\hline Support & & & 0.566 & \\
\hline Difficulty & & & & 0.833 \\
\hline Challenge & & & & 0.885 \\
\hline Stress & & & & 0.477 \\
\hline
\end{tabular}

To assess between groups differences of SWLS, we assigned 27 percent of participants who scored the highest in SWLS to high SWLS group and 27 percent of participants who scored the lowest to low SWLS group. We examined the differences between groups with respect to four PPA factors with an independent-samples T test. The results showed that the high-SWLS group scored significantly higher than the low-SWLS group on the Project Meaning, Project Control and Project Interpersonal Relationship factors and lower than the low-SWLS group on the Project Strain factor but not significantly (see Table 2).

Table 2

Descriptive Statistics and $t$ Values for PPA Factors for Low-SWLS and High-SWLS Groups (N=170)

\begin{tabular}{|c|c|c|c|c|c|c|}
\hline \multirow[b]{2}{*}{ PPA factor } & \multicolumn{2}{|c|}{ Low SWLS } & \multicolumn{2}{|c|}{ High SWLS } & \multirow[b]{2}{*}{$t$} & \multirow[b]{2}{*}{$p$} \\
\hline & $M$ & $S D$ & $M$ & $S D$ & & \\
\hline Project Meaning & 30.95 & 4.693 & 33.07 & 4.912 & 2.027 & 0.046 \\
\hline Project Control & 32.64 & 6.709 & 36.86 & 4.952 & 3.282 & 0.002 \\
\hline Project Interpersonal Relationship & 19.63 & 4.623 & 21.96 & 3.790 & 2.510 & 0.014 \\
\hline Project Strain & 15.11 & 4.666 & 13.73 & 4.343 & -1.407 & 0.163 \\
\hline
\end{tabular}

Likewise, to assess between groups differences of emotional experience (Positive Affect), we assigned 27 percent of participants who scored the highest in PA to high-PA group and 27 percent of participants who scored 
A study on the relationship of college students' personal projects to subjective well-being

the lowest to low-PA group. We also examined the differences between groups with respect to four PPA factors with an independent-samples T test. The results showed that the high-PA group scored significantly higher than the low-PA group on the PPA factor Project Meaning, Project Control and Project Interpersonal Relationship. The high-PA group scored higher than the low-PA group on the Project Strain but not significantly (see Table 3).

Table 3

Descriptive Statistics and $t$ Values for PPA Factors for Low-PA and High-PA Groups $(N=170)$

\begin{tabular}{|c|c|c|c|c|c|c|}
\hline \multirow[b]{2}{*}{ PPA factor } & \multicolumn{2}{|c|}{ Low PA } & \multicolumn{2}{|c|}{ High PA } & \multirow[b]{2}{*}{$t$} & \multirow[b]{2}{*}{$p$} \\
\hline & $M$ & $S D$ & $M$ & $S D$ & & \\
\hline Project Meaning & 30.09 & 5.058 & 34.61 & 3.687 & 4.509 & 0.001 \\
\hline Project Control & 32.11 & 6.381 & 37.73 & 5.296 & 4.233 & 0.003 \\
\hline Project Interpersonal Relationship & 19.17 & 4.709 & 21.56 & 3.587 & 2.515 & 0.014 \\
\hline Project Strain & 13.50 & 4.455 & 14.01 & 4.369 & 0.513 & 0.609 \\
\hline
\end{tabular}

A similar independent-samples T test was conducted to examine the differences between high-NA (Negative Affect) group and low-NA group with respect to four PPA factors. The results showed that there no significant differences between the two groups on all four PPA factors (Table 4).

\section{Table 4}

Descriptive Statistics and $t$ Values for PPA Factors for Low-NA and High-NA Groups $(N=170)$

\begin{tabular}{|c|c|c|c|c|c|c|}
\hline \multirow[b]{2}{*}{ PPA factor } & \multicolumn{2}{|c|}{ Low NA } & \multicolumn{2}{|c|}{ High NA } & \multirow[b]{2}{*}{$t$} & \multirow[b]{2}{*}{$p$} \\
\hline & $M$ & $S D$ & $M$ & $S D$ & & \\
\hline Project Meaning & 41.11 & 5.616 & 39.50 & 5.690 & -1.265 & 0.210 \\
\hline Project Control & 43.58 & 7.610 & 41.15 & 7.595 & -1.426 & 0.158 \\
\hline Project Interpersonal Relationship & 12.70 & 3.836 & 12.45 & 3.396 & -0.313 & 0.755 \\
\hline Project Strain & 10.53 & 4.189 & 10.83 & 3.037 & 0.364 & 0.717 \\
\hline
\end{tabular}

We calculated bivariate correlation coefficients between the SWLS and PPA factors for the entire sample before assessing predictors of scores of subjective well-being. We only included measures of PPA factors with statistically significant associations with SWLS scores in later regression analyses. SWLS scores had significant positive associations with the PPA factors Project Control, $r=0.260, p<0.01$, and Project Interpersonal Relationship, $r=0.171, p<0.05$. Multiple regression analyses were performed to assess predictors of SWLS scores with Project Control and Project Interpersonal Relationship as independent variables and SWLS as dependent variable. The results showed that only Project Control entered stepwise into the equations and accounted for $6.3 \%$ of the variance of SWLS. With respect to PPA dimensions, only dimension Progress entered into the equations and accounted for $7.5 \%$ of the variance of SWLS. The results indicated that PPA factor Project Control and PPA dimension Progress could be significant predictors of SWLS.

Table 5

A Summary of Multiple Regressions of the Mean of PPA Factors and Dimensions on SWLS (N=316)

\begin{tabular}{lcccccccc}
\hline \multicolumn{1}{c}{ Variable } & $B$ & Std. Error & Beta & $t$ & Sig. & $R$ & $R^{2}$ & Adjusted R $^{2}$ \\
\hline (Constant) & 9.905 & 2.383 & & 4.157 & 0.000 & & & 0.063 \\
Project Control & 0.225 & 0.067 & 0.263 & 3.367 & 0.001 & 0.263 & 0.069 & 0.075 \\
(Constant) & 10.938 & 1.892 & & 5.782 & 0.000 & & & 0.081 \\
Progress & 0.976 & 0.265 & 0.285 & 3.684 & 0.000 & 0.285 & 0.085 \\
\hline
\end{tabular}

Similarly, before assessing predictors of scores of Positive Affect and Negative Affect, we calculated bivariate correlation coefficients between PA/NA and PPA factors. We only included measures of PPA factors with statistically significant associations with PA/NA scores in later regression analyses. PA scores had significant positive associations with the PPA factors Project Meaning, $r=0.389, p<0.01$, Project Control, $r=0.350, p<0.01$, and Project Interpersonal Relationship, $r=0.232, p<0.01$. Multiple regression analyses were performed to assess predictors of PA scores with Project Meaning, Project Control and Project Interpersonal Relationship as independent variables and PA as dependent variable. The results showed that only Project 
Meaning entered stepwise into the equations and accounted for $14.8 \%$ of the variance of PA. With respect to PPA dimensions, only dimension Responsibility entered into the equations and accounted for $13.3 \%$ of the variance of PA. On the other hand, NA scores had significant negative associations with the PPA factors Project Meaning, $r=-0.203, p<0.05$, Project Control, $r=-0.199, p<0.05$. They also had significant positive associations with Project Strain, $r=0.174, p<0.01$. Multiple regression analyses were performed to assess predictors of NA scores with the three PPA factors as independent variables and PA as dependent variable. The results showed that only Project Meaning entered stepwise into the equations and accounted for 3.5\% of the variance of NA. With respect to PPA dimensions, only dimension Value Congruency entered into the equations and accounted for $3.3 \%$ of the variance of PA. The results indicated that PPA factor Project Meaning was a significant predictor of both PA and NA, and PPA dimension Responsibility could be a significant predictor of PA and dimension Value Congruency a significant predictor of NA respectively.

\section{Table 6}

A Summary of Multiple Regressions of the Mean of PPA Factors and Dimensions on PA and NA (N=316)

\begin{tabular}{|c|c|c|c|c|c|c|c|c|c|}
\hline & Variable & $B$ & Std. Error & Beta & $t$ & Sig. & $R$ & $R^{2}$ & Adjusted $R^{2}$ \\
\hline & (Constant) & 6.901 & 4.714 & & 1.464 & 0.145 & & & \\
\hline \multirow[t]{2}{*}{$\mathrm{PA}$} & Project Meaning & 0.748 & 0.144 & 0.389 & 5.211 & 0.000 & 0.389 & 0.152 & 0.148 \\
\hline & (Constant) & 11.927 & 3.970 & & 3.004 & 0.003 & & & \\
\hline \multirow[t]{2}{*}{ PA } & Responsibility & 2.414 & 0.488 & 0.373 & 4.950 & 0.000 & $0.373^{\mathrm{a}}$ & 0.139 & 0.133 \\
\hline & (Constant) & 39.890 & 5.383 & & 7.410 & 0.000 & & & \\
\hline \multirow[t]{2}{*}{ NA } & Project Meaning & -0.417 & 0.164 & -0.203 & -2.544 & 0.012 & 0.203 & 0.041 & 0.035 \\
\hline & (Constant) & 36.713 & 4.290 & & 8.558 & 0.000 & & & \\
\hline NA & Value Congruency & -1.318 & 0.531 & -0.199 & -2.484 & 0.014 & 0.199 & 0.040 & 0.033 \\
\hline
\end{tabular}

\section{Discussion}

The results of this study indicated that with respect to viewing idiosyncratic and goal-oriented activities, there were fundamental differences between college students who were happier and experienced more positive emotions and those who were less happy and experienced less positive emotions. Compared with their less happy peers, students who were happier rated their personal projects as more congruent with and fulfilling of their values and identity. Happier students appeared to sense a positive self and to be more responsible. In contrast, less happy students perceived their personal projects as more alien to the fulfillment of their identities. They rated current projects as less important, less responsible, less congruent with their values, and less consistent with their identities. Although positive emotions are generally considered to be negatively associated with negative emotions, there weren't significant differences between students who experienced more negative emotions and those who experienced less negative emotions, which implies that positive emotions explain individuals' happiness better than negative emotions despite the fact that the latter can, in some cases, be an indicator of well-being (Fredrickson, 2002).

Another important but not surprising finding is that Project Control was proved to be a reliable predictor of SWLS in the regression analyses, which is consonant with some previous research (Ruehlman \& Wolchik, 1988). This is probably because well-being is usually associated with expectations about goal attainment and Project Control may indicate that goal attainment is likely. Therefore, PPA factor Project Control—maybe named differently in other studies-is not only a significant predictor of well-being but also a predictor of other personality traits such as optimism and pessimism (Jackson et al., 2002). Among all dimensions of Project Control, only progress emerged as the reliable predictors of SWLS. Progress means the extent to which personal projects are supposed to be achieved. Though the degree to which self-reported perceptions of personal projects are associated with actual behavior and performance of personal projects is unknown, perceptions of goals do influence actions according to the expectancy-valence theory (Feather, 1990). Thus, Progress predicated SWLS and Positive Emotion better than other dimensions of Project Control.

With respect to affect, Project Meaning, instead of Project Control, became the predictor. This finding of the 
A study on the relationship of college students' personal projects to subjective well-being

study supports some researchers' ideas that the affective and cognitive components of Subjective Well-being are somewhat distinctive (Beiser, 1974; Campbell, Converse, \& Rogers, 1976; DeHaes, Pennink, \& Welvaart, 1987). Pavot and Diener (1993) pointed out that there is evidence that cognitive and affective measures form separate factors. Because affect and life satisfaction are different, so are the factors and dimensions that can influence and predict them. Affective reactions are often responses to immediate factors and of short duration, whereas life satisfaction ratings can reflect a long-term perspective. And of course, compared with Project Meaning, Project Control reflects a longer duration and a long-term perspective better. Besides, a person's conscious evaluation of her or his life circumstances may reflect conscious values and goals. In contrast, affective reactions may reflect unconscious motives. Again, Project Control reflects conscious values and goals better. Another idea that Pavot and Diener's hold is that they think people may ignore or deny negative emotional reactions while still recognizing the undesirable factors in their lives, which explains why there weren't significant differences between high-NA students and low-NA students with respect to rating all PPA factors.

While it is commonly agreed that Project Control is a reliable predictor of well-being, several results have shown that personal project stress is associated with different aspects of well-being, too. For example, low personal project stress is related to life satisfaction (Little, 1989; Wallenius, 1999, 2000); high project stress is associated with negative affect (Pychyl \& Little, 1998). Ruehlman and Wolchik (1988) argued that Project Strain (difficulty, challenge, stress, etc.) may affect well-being because perceptions of strain suggest potential failure of goal attainment. However, this study showed that the differences between happier students and less happy students were not significant in regard of Project Strain. This is probably because of the idiosyncratic activities college students have. Though some researchers found that college students' personal projects were quite different from those of other groups of individuals (Alexander \& Langer, 1990; Smelser \& Erikson, 1980), little was known about consequences these differences cause. By reviewing all personal projects students generated in this study, we found that types of the majority of those projects were or were related to academic activities. For happier students as well as less happy students, both faced similar types of academic activities. And it is likely that happier students may perceive their goals as difficult, challenging and stressful but at the same time they may also think of themselves as being capable of controlling and completing their projects. In other words, that happier students perceived their goals as difficult, challenging and stressful didn't prevent them from having a significant role in carrying out their projects. Therefore, happier students' perceptions of difficulty, challenge, and stress of their activities were probably the same with those of less happy students. Furthermore, some research showed that when choosing goals to accomplish, individuals who scored highly in achievement tests were less likely to choose goals that were too difficult or too easy (McClelland \& Franz, 1992). This study suggests that given that college students focus on similar personal projects, that they experience moderate difficulty, challenge, and even stress of achieving their goals, would to some extent, heighten rather than reduce their well-being. This explanation accounts for why Project Strain is not a reliable predictor of well-being though the result of the study isn't consonant with some earlier work.

The original PPA provides a list of predefined dimensions that don't load onto an interpersonal relationship factor (Little \& Gee, 2007). But because PPA is a flexible, open-ended series of assessment modules that encourage researchers to add or remove dimensions according to their research interest, we decided to revise these dimensions to explore the relationship between personal projects and well-being in a cultural context--in a Chinese cultural context, to be more exact. Chinese people behave differently from westerners in regard of goal attainment. Major patterns in Chinese activity-organization are closely related to interpersonal relationship (Weakland, 1950). Compared with their western peers, Chinese students' perceptions of their goals and behaviors may be more influenced by their relationships with their relatives, friends and people around them. While we removed some dimensions from the PPA list that are not appropriate for Chinese culture context, we added three dimensions that are supposed to be related to interpersonal relationship. The three dimensions finally loaded onto a factor of it successfully, which implies that interpersonal relationship is an important part of the structure of Chinese students' personal projects. The results indicated that happiness not only relates to Project Meaning and Project Control but also to Project Interpersonal Relationship, which suggests that happier students 
Wang, $\mathrm{H}$.

are more likely to have a better relationship with people close to them than less happy students.

To conclude, participants who scored higher in SWLS and pleasant affect were more likely to have higher scores in perceptions of Project Meaning, Project Control and Project Interpersonal Relationship. There weren't significant differences between high and low SWLS groups and high and low pleasant affect groups with respect to perceptions of Project Strain. Project Control emerged as a reliable predictor of SWLS whereas Project Meaning as a reliable predictor of Pleasant Affect. Project Strain appeared to have no significant effects on subjective well-being.

Acknowledgement: This study is supported by Chongqing Key Research Base for Humanities and Social Science.

\section{References}

Alexander, C.N. \& Langer, E.J. (1990). Higher stages of human development: Perspectives on adult growth. Oxford: Oxford University Press.

Andrews, F. M., \& Withey, S. B. (1976). Social indicators of well-being America's perception of life quality. New York: Plenum Press. http://dx.doi.org/10.1007/978-1-4684-2253-5

Austin, J. T., \& Vancouver, J. F. (1996). Goal constructs in psychology: Structure, process, and content. Psychological Bulletin, 120, 338-375. http://dx.doi.org/10.1037/0033-2909.120.3.338

Beiser, M. (1974). Components and correlates of mental well-being. Journal of Health and Social Behavior, 15, 320-327. http://dx.doi.org/10.2307/2137092

Brunstein, J. C. (1993). Personal goals and subjective well-being: A longitudinal study. Journal of Personality and Social Psychology, 65(5), 1061-1070. http://dx.doi.org/10.1037/0022-3514.65.5.1061

Campbell, A., Converse, P. E., \& Rogers, W. L. (1976). The quality of American life. New York: Russell Sage Foundation.

Cantor, N., Norem, J. K., Niedenthal, P. M., Langston, C. A., \& Brower, A. M. (1987). Life tasks, self-concept ideals, and cognitive strategies in a life transition. Journal of Personality and Social Psychology, 53, 1178-1191. http://dx.doi.org/10.1037/0022-3514.53.6.1178

Carr, A. (2004). Positive psychology: The science of happiness and human strengths. New York: Ruoutledge. Chamberlain, K. (1988). On the structure of well-being. Social Indicators Research, 20, 581-604.

De Neve, K. M. (1999). Happy as an extraverted clam? The role of personality for subjective well-being. Psychological Science, 8(5), 141-144.

DeHaes, J. C., Pennink, B. J. W., \& Welvaart, K. (1987). The distinction between affect and cognition. Social Indicators Research, 19, 367-378. http://dx.doi.org/10.1007/BF00300368

Diener, E. (1984). Subjective well-being. Psychological Bulletin, 95, 542-575. http://dx.doi.org/10.1037/0033-2909.95.3.542

Diener, E. (1994). Assessing subjective well-being: Progress and opportunities. Social Indicators Research, 31, 103-157. http://dx.doi.org/10.1007/BF01207052

Diener, E., \& Emmons, R. A. (1984). The independence of positive and negative affect. Journal of Personality and Social Psychology, 47, 1105-1117. http://dx.doi.org/10.1037/0022-3514.47.5.1105

Diener, E., Emmons, R. A., Larsen, R. J., \& Griffin, S. (1985). The satisfaction with life scale. Journal of Personality Assessment, 49, 71-75. http://dx.doi.org/10.1207/s15327752jpa4901_13

Emmons, R. A. (1986). Personal strivings: An approach to personality and subjective well-being. Journal of Personality and Social Psychology, 51, 1058-1068. http://dx.doi.org/10.1037/0022-3514.51.5.1058

Emmons, R. A. (1991), Personal strivings, daily life events, and psychological and physical well-being. Journal of Personality, 59, 453-472. http://dx.doi.org/10.1111/j.1467-6494.1991.tb00256.x

Fredrickson, B. L. (2002).Positive emotions. In C.R. Snyder \& S. J. Lopez (Eds.), Handbook of positive psychology (pp.120-134). New York: Oxford University Press. 
A study on the relationship of college students' personal projects to subjective well-being

Heckhausen, J. (1999). Developmental regulation in adulthood: Age-normative and sociostructural constraints as adaptive challenges. New York: Cambridge University Press.

Jackson, T., Weiss, K. E., Lundquist, J., \& Soderlind, A. (2002). Perceptions of goal-directed activities of optimists and pessimists: A Personal Projects Analysis. Journal of Psychology, 136(5),

521-532. http://dx.doi.org/10.1080/00223980209605548

Jennings, K. D., \& Dietz, L. J. (2003). Mastery motivation and goal persistence in young children. In M. H. Bornstein, L. Davidson, C. L. Keyes, \& K. A. Moore (Eds.), Well-being: Positive development across the life course (pp. 295-309). Mahwah, NJ: Erlbaum.

Karoly, P., \& Anderson, C. W. (2000). The long and short of psychological change: Toward a goal-centered understanding of treatment durability and adaptive success. In C. R. Snyder, \& R. E. Ingram (Eds.), Handbook of psychological change (pp. 154-176). New York: Wiley.

Lecci, L., Karoly, P., Briggs, C., \& Kuhn, K. (1994). Specificity and generality of motivational components in depression: A personal projects analysis. Journal of Abnormal Psychology, 103, 404-408. http://dx.doi.org/10.1037/0021-843X.103.2.404

Little B. R. (1987). Personal project analysis: A new methodology for counseling psychology. Natcon, 13, 591-614.

Little B. R. (1993). Personality and distributed self: Aspects of a conative psychology. In J. Suls (Ed.), Psychological perspectives on the self (pp. 157-181). Hillsdale, NJ: Erlbaum.

Little, B. R. (1983). Personal projects: A rationale and method for investigation. Environment and Behavior, 15 (3), 273-309. http://dx.doi.org/10.1177/0013916583153002

Little, B. R. (1989). Personal Projects Analysis: Trivial pursuits, magnificent obsessions, and the search for coherence. In D. M. Buss \& N. Cantor (Eds.), Personality psychology: Recent trends and emerging directions (pp. 15-31). New York: Springer-Verlag. http://dx.doi.org/10.1007/978-1-4684-0634-4_2

Little, B. R. (1993). Personal projects and the distributed self: Aspects of a conative psychology. In J. Suis (Ed), Psychological perspectives on the self. (Vol. 4, pp. 157-181). Hillsdale, NJ: Erlbaum.

Little, B. R. (1998). Personal project pursuit: Dimensions and dynamics of personal meaning. In P. T. P. Wong \& P. S. Fry (Eds.), The human question for meaning: A handbook of psychological research and clinical applications (pp. 197-221). Thousand Oaks, CA: Sage.

Little, B. R., \& Gee, T. L. (2007). The methodology of personal projects analysis: Four modules and a funnel. In B. R. Little, K. Salmela-Aro, \& S. D. Phillips (Eds.), Personal project pursuit: Goals, action and human flourishing (pp. 51-93). Mahwah, NJ: Lawrence Erlbaum Associates.

McClelland, D. C., \& Franz, C. E. (1992). Motivational and other sources of work accomplishment in mid-life: A longitudinal study. Journal of Personality, 60, 679-707. http://dx.doi.org/10.1111/j.1467-6494.1992.tb00270.x

McGregor, I., \& Little, B. R. (1998). Personal projects, happiness, and meaning: On doing well and being yourself. Journal of Personality and Social Psychology, 74, 494-512. http://dx.doi.org/10.1037/0022-3514.74.2.494

Palys, T. S., \& Little, B. R. (1983). Perceived life satisfaction and the organization of personal project systems. Journal of Personality and Social Psychology, 44, 1221-1230. http://dx.doi.org/10.1037/0022-3514.44.6.1221

Pavot, W., \& Diener, E. (1993). Review of the satisfaction with life scale. Psychological Assessment, 5 , 164-172. http://dx.doi.org/10.1037/1040-3590.5.2.164

Presseau, J., Sniehotta, F.F., Francis, J.J., \& Little, B.R. (2008). Personal projects analysis: Opportunities and implications for multiple goal assessment, theoretical integration, and behavior change. The European Health Psychologist, 10, 32-36.

Pychyl, T.A., \& Little, B.R. (1998). Dimensional specificity in the prediction of subjective well-being: Personal Projects in pursuit of the Ph.D. Social Indicators Research, 45, 423-473. http://dx.doi.org/10.1023/A:1006970504138

Ruehlman, L. S. \& Wolchik, S. A. (1988). Personal goals and interpersonal support and hindrance as factors in psychological distress and well-being. Journal of Personality and Social psychology, 55, 293-301. 
Wang, $\mathrm{H}$.

http://dx.doi.org/10.1037/0022-3514.55.2.293

Salmela-Aro, K. \& Nurmi, J. E. (1997). Goal contents, well-being and life context during transition to university - a longitudinal study. International Journal of Behavioral Development, 20, 471-491. http://dx.doi.org/10.1080/016502597385234

Salmela-Aro, K. (1992). Struggling with self. Personal projects of students seeking psychological counseling. Scandinavian Journal of Psychology, 33, 330-338. http://dx.doi.org/10.1111/j.1467-9450.1992.tb00922.x

Seligman, M.E.P. (2002). Authentic Happiness: Using the New Positive Psychology to Realize Your Potential for Lasting Fulfillment. New York: Free Press.

Smelser, N. J., \& Erikson, E. H. (1980). Themes of work and love in adulthood. Cambridge, MA: Harvard University Press.

Stock, W. A., Okun, M. A., \& Benin, M. (1986). Structure of subjective well-being among the elderly. Psychology and Aging, 1, 91-102. http://dx.doi.org/10.1037/0882-7974.1.2.91

Suh, E., Diener, E., Oishi, S., \& Triandis, H. C. (1998). The shifting basis of life satisfaction judgments across cultures: Emotions versus norms. Journal of Personality and Social Psychology, 74, 482-493. http://dx.doi.org/10.1037/0022-3514.74.2.482

Wallenius M. (2000). Personal project level of abstraction and project conflict: Relations to psychological well-being. European Journal of Personality, 14, 171-184. http://dx.doi.org/10.1002/(SICI)1099-0984(200003/04)14:2<171::AID-PER352>3.0.CO;2-D

Wallenius, M. (1999). Personal projects in everyday places: Perceived supportiveness of the environment and psychological well-being. Journal of Environmental Psychology, 19, 131-143. http://dx.doi.org/10.1006/jevp.1998.0118

Weakland, J. H. (1950). The organization of action in Chinese culture. Psychiatry, 13, 361-370. 